Article

\title{
Effects of Ball Milling Processing Conditions and Alloy Components on the Synthesis of $\mathrm{Cu}-\mathrm{Nb}$ and Cu-Mo Alloys
}

\author{
Xuekun Shang ${ }^{1}\left({ }^{\circ}\right.$, Xitao Wang ${ }^{1}\left(\mathbb{D}\right.$ and Silian Chen ${ }^{2, *}$ \\ 1 Collaborative Innovation Center of Steel Technology, University of Science and Technology Beijing, \\ Beijing 100083, China; xkshang0518@outlook.com (X.S.); xtwang@ustb.edu.cn (X.W.) \\ 2 Central Iron and Steel Research Institute, Beijing 100081, China \\ * Correspondence: chensilian@cisri.com.cn
}

Received: 19 March 2019; Accepted: 12 April 2019; Published: 15 April 2019

check for updates

\begin{abstract}
The effects of processing parameters in ball milling and the different behaviors of $\mathrm{Cu}-\mathrm{Nb}$ and $\mathrm{Cu}-\mathrm{Mo}$ alloys during milling were investigated. High powder yields can be obtained by changing the BPR value and ball size distribution and no clear dependence of BPR value on powder yield can be found from the experiment results. The addition of oxygen can largely reduce the effect of excessive cold welding during ball milling. A "two-step" ball milling method was introduced to evaluate the different evolution processes and morphologies in different alloys. With $8 \mathrm{~h}$ pre-milling, this method considerably benefits the oxidation process of Mo and shows its promising potential in the synthesis of immiscible alloys. Based on the experiment results and analysis, we suggest that the different behaviors of $\mathrm{Cu}-\mathrm{Nb}$ and $\mathrm{Cu}-\mathrm{Mo}$ alloys are related to the shear modules and different tendencies to be oxidized.
\end{abstract}

Keywords: mechanical alloying; two-step ball milling; $\mathrm{Cu}$ alloy; immiscible alloy; SPEX milling

\section{Introduction}

Mechanical alloying (MA) is a well-known way in processing advanced materials involving repeated welding and fracturing the powder particles in a high energy ball mill [1,2]. First developed by Benjamin and his co-workers in 1970s [3,4], this processing method has been shown the potential in synthesizing supersaturated solid solutions, amorphous alloys, nano-crystalline, intermetallics, and oxide dispersion-strengthened alloys [5]. As a simple, elegant, efficient non-equilibrium processing method, MA is widely used to synthesis bulk supersaturated solid solutions used for many engineering applications. Large doses of energy are applied to powder particles during milling processing to produce nano-sized grains and supersaturated state of solute atoms in many alloy systems. However, the large amount of energy consumed when milling could be an obstacle in industrial application of this method [6]. Another problem is the low powder yield after MA, powder particles are sometimes easily get cold-welded to each other because of the heavy plastic deformation during milling, especially if they are ductile. Although a process control agent (PCA) can be used to reduce the final particle size and increase the powder yield, one need to consider the contamination level and possible interactions between the powders and the components in the PCA during the milling process [2,7-13]. Other than that, a number of process variables like milling time, milling speed, milling atmosphere, temperature of milling and the grinding medium also have effects on the final state of powder [14-17]. With all the milling parameters, MA is indeed a very complex process. Furthermore, all these process parameters are not completely independent, which makes it more difficult to increase the ball milling efficiency and to achieve the desired product phase or microstructure. Thus, many efforts have been 
made by investigators to get good understanding of the mechanisms related to the influences of processing parameters.

Ward et al. investigated milling process using different ball sizes and ball to powder mass ratios (BPR), introduced an expression for the milling dose to gauge the milling progress and found that the efficiency could remain constant over a range of BPR [16]. Razavi-Tousi et al. found that at a fixed ball-to-powder ratio, a change in ball size can significantly change the steady state milling time [6]. Gotor et al. studied the dependence of the ignition time $\left(t_{i g}\right)$ on the main parameters of the milling process such as spinning rate, powder charge, type and number of balls, established a direct relationship between the inverse of the ignition time and the power of the planetary mill [18]. Mojarrad et al. investigated the effect of filling ratio of vial (FRV) on the thermal behavior of $\mathrm{Al}-\mathrm{Fe}_{2} \mathrm{O}_{3}$ thermite, showed the importance of FRV especially for mechanochemical synthesis and mechanically-activated combustion synthesis processes [19]. Broseghini et al. discussed the effect of jar shape on high-energy planetary ball milling efficiency and achieved enhanced comminution by suitably re-designing the jar shape [20]. Additionally, the effect of atmosphere and milling time were studied, Madavali et al. found that oxygen contamination played an important role in determining the final particle size and microstructure of the powder [21]. Similarly, Hegedûs et al. found the presence of oxygen obstructed the sticking of milled material and the milling medium, and the intrinsic strength of a metal determined the whether or not occurrence of spherical particles [22]. Caballero et al. also investigated the effect of ammonia and found that a short-time ammonia gas flow notably improved the hardness and strength of an Al-based alloy [23]. With more and more reports in literature, almost all the milling parameters have been studied to optimize the process, except that, we believe it is also worthwhile to consider the behaviors of different alloy components in milling. The mechanical or chemical properties of the milled materials could play a decisive role in ball milling.

In this work, we attempted to optimize the milling process by changing the ball size distribution and BPR. Copper oxide $(\mathrm{CuO})$ powder was added into copper alloy system $(\mathrm{Cu}-\mathrm{Nb}, \mathrm{Cu}-\mathrm{Mo})$ not only to evaluate the influence of oxygen on the final state of powder particles, but also to obtain oxide dispersion-strengthened (ODS) copper alloys. A "two-step" ball milling method was introduced with the addition of $\mathrm{CuO}$ to illustrate the oxidation process of precipitates. Furthermore, we discussed the influence of different element properties on the behaviors of two alloy components ( $\mathrm{Nb}$ and $\mathrm{Mo}$ ) in mechanical alloying.

\section{Materials and Methods}

Powders of $\mathrm{Cu}$ (99.9\% purity, APS 10 micron), Ag (99.9\% purity, APS 4-7 micron), Nb (99.99\% purity, APS 10 micron) and Mo (99.95\% purity, APS 3-7 micron) purchased from Alfa Aesar (Ward Hill, MA, USA), were ball milled in a SPEX 8000D Dual Mixer/Mill ${ }^{\circledR}$ (SPEX SamplePrep, Metuchen, NJ, USA). The SPEX shaker mill, which is most commonly used for laboratory investigations, operates by agitating a small grinding container with a capacity up to $5.5 \times 10^{-5} \mathrm{~m}^{3}$ in three mutually perpendicular directions at approximately $20 \mathrm{~Hz}(1190 \mathrm{rpm})$ [1]. Stainless steel balls with three different sizes $(6.35 \mathrm{~mm}$, $9.525 \mathrm{~mm}$, and $12.7 \mathrm{~mm}$ in diameter) were used in a hardened $440 \mathrm{C}$ stainless steel made grinding vial. Copper alloys with nominal atomic fraction $\mathrm{Cu}_{85} \mathrm{Nb}_{5} \mathrm{Ag}_{10}$ was investigated and the milling process was performed under argon atmosphere with different ball size distributions and BPR changing from 0.83 to 5.93 at room temperature. The addition of 10 at. $\%$ Ag prevented severe cold welding during milling and at the same time Ag powder acted as a marker for monitoring the deformation and mixing in the $\mathrm{Cu}$ lattice [24].

Furthermore, copper oxide $(\mathrm{CuO})$ powder was added in the beginning of milling to introduce oxygen into the $\mathrm{Cu}-\mathrm{Nb} / \mathrm{Cu}-\mathrm{Mo}$ alloy systems. All the to-be-milled powders were kept and loaded into the grinding vial inside a purified argon glovebox. After 10 to $30 \mathrm{~h}$ milling time, the milled powders were then collected and weighed in order to determine the powder yield. In addition, a "two-step" ball milling procedure was performed for comparison. The processing of the powders involved two steps: pure $\mathrm{Cu}, \mathrm{Nb} / \mathrm{Mo}$ and $\mathrm{Ag}$ powders were mixed and ball milled for $8 \mathrm{~h}$ to reach steady state after 
which $\mathrm{Nb} / \mathrm{Mo}$ precipitates finely dispersed in copper matrix. $\mathrm{CuO}$ powder was then added at the beginning of the second step milling, powders were sampled after different interval of milling time $(1,2,4,6,10$, and $20 \mathrm{~h})$. The nominal atomic fractions of the alloys are $\mathrm{Cu}_{65} \mathrm{Nb}_{5} \mathrm{Ag}_{10}(\mathrm{CuO})_{10}$ and $\mathrm{Cu}_{65} \mathrm{Mo}_{5} \mathrm{Ag}_{10}(\mathrm{CuO})_{10}$, respectively.

Subsequent to ball milling, an X-ray diffraction (XRD) instrument Rigaku MiniFlex-600 (Rigaku, Tokyo, Japan) with CuK $\alpha$ radiation (1.5406 $\AA$ ) was used to obtain XRD patterns for phase determination, solubility and grain size measurement of the powders, with the range of $2 \theta$ from $25^{\circ}$ to $60^{\circ}$, in a scan speed of $1^{\circ} / \mathrm{min}$ and a step width of $0.02^{\circ}$. The microstructures of some powder samples were characterized by scanning transmission electron microscopy (STEM) performed on a JEOL 2010F EF-FEG microscopes (JEOL, Ltd., Tokyo, Japan). STEM samples were prepared by FEI Helios 600 focused ion beam (FIB) (FEI Company, Hillsboro, OR, USA).

\section{Results and Discussion}

\subsection{Optimization of BPR and Ball Size Distribution}

The BPR has a significant effect on the time required to achieve a steady state or particular phase in ball milling. Generally, a high BPR means a bigger mass or quantity of milling balls, thus increase the possibility of collisions to each other for the grinding medium. Consequently, more energy is used to accelerate the alloying process after transformed to the particles. Many related studies provided the BPR as a principal parameter to describe ball milling experiments. However, same BPR values can be obtained either by changing the number, size, or density of balls or changing the powder weight and balls at the same time. Milling was found to have different efficiency despite the same BPR [25], different ball size distributions at a fixed BPR significantly changed the steady state milling time [6]. The present work, however, is more concerned with the powder yields of ball milling at different BPR values and ball size distributions.

Table 1 gives the summary of the milling experiments performed on $\mathrm{Cu}_{85} \mathrm{Nb}_{5} \mathrm{Ag}_{10}$ alloy. Three different sizes of balls, referred to as $\mathrm{S}$ (small, $1 / 4$ inch in diameter, $1.03 \mathrm{~g}$ ), $\mathrm{M}$ (medium, $3 / 8$ inch in diameter, $3.5365 \mathrm{~g}$ ) and L (large, 1/2 inch in diameter, $8.355 \mathrm{~g}$ ), were used in the milling to optimize the ball size distribution and BPR, the numbers before $\mathrm{S}, \mathrm{M}$, and $\mathrm{L}$ in column $\mathrm{D}$ are the quantity of used balls. All the ball milling experiments were performed for $10 \mathrm{~h}$, interrupted every $2 \mathrm{~h}$ to check the status of the powder and cool down the vial. It should be noted that the powder yield data (with values greater than zero) in the table correspond to single experiments. Although we repeated the configuration in the sample 7 multiple times without recording the powder yields and those with zero powder yields for confirmation, it is an accepted fact that the alloying process among different powder particles happens when the balance between welding and fracturing achieved and reducing the effect of excessive cold welding is the key point to obtain good powder yield. Many investigators believe that a higher BPR value could result in more cold welding rather than fracturing and, thus, reduces the amount of powder produced. However, very different powder yields are achieved with similar (sample 2 and sample 5) or even the same (sample 3 and sample 4) BPR values as shown in Table 1. Both high and low BRP values can lead to good powder yields. Obviously, no clear dependence of BPR value on powder yield can be found from the experiment results. Perhaps the size and amount of balls have more influence on the powder yield in a small capacity, high-energy mill, such as the SPEX mill in which the BPR values are relatively low $(<10: 1)$. It was reported that the size of the grinding medium could affect the milling efficiency and the final constitution of powder [26-29]. Investigators ascribed it to the differences in the temperatures and the input energies of different grinding medium. Moreover, the use of different sizes of balls in the same experiment could minimize cold welding and thus the less powder coated onto the balls [30]. It was suggested that different sized balls will produce shearing forces and help to detach the powder on the balls. Thus, the powder yield could be higher with a combination of different sizes of balls. On the other hand, a combination of different sized balls helps to prevent a well-defined trajectory of moving balls. We manage to get high powder 
yields with different sized balls in sample 2 and sample 10, but we have an exception in sample 9 . Therefore, it is complex to comprehend how the ball size difference affect the balance between welding and fracturing of powder particles, yet we suggest that the velocity change of balls and the hardness change of powder particles under different temperatures play an important role here.

Table 1. Summary of the milling experiments performed on $\mathrm{Cu}_{85} \mathrm{Nb}_{5} \mathrm{Ag}_{10}$ alloy. $\mathrm{N}$ is the label of the sample in each run. $M_{a}$ is the mass of the powder added into the milling vial. $M_{b}$ is the mass of the powder recovered after mill (measured). $\mathrm{D}$ is the detail about the size and quantity of balls used in a run. BPR is the ball to powder mass ratio. $\mathrm{P}$ is the powder yield of a run $\left(=\frac{M_{b}}{M_{a}} \times 100 \%\right)$.

\begin{tabular}{cccccc}
\hline $\mathbf{N}$ & $\mathbf{D}$ & $\boldsymbol{M}_{\boldsymbol{a}}$ & $\mathbf{B P R}$ & $\boldsymbol{M}_{\boldsymbol{b}}$ & $\mathbf{P}$ \\
\hline 1 & $1 \mathrm{~L}$ & $10 \mathrm{~g}$ & 0.8355 & $5.85 \mathrm{~g}$ & $58.5 \%$ \\
2 & $1 \mathrm{~S} 1 \mathrm{M}$ & $5 \mathrm{~g}$ & 0.912 & $3.76 \mathrm{~g}$ & $75.2 \%$ \\
3 & $2 \mathrm{M}$ & $10 \mathrm{~g}$ & 0.7073 & $2.83 \mathrm{~g}$ & $28.3 \%$ \\
4 & $3 \mathrm{M}$ & $15 \mathrm{~g}$ & 0.7073 & 0 & 0 \\
5 & $3 \mathrm{M}$ & $10 \mathrm{~g}$ & 1.059 & 0 & 0 \\
6 & $4 \mathrm{M}$ & $10 \mathrm{~g}$ & 1.41 & 0 & 0 \\
7 & $7 \mathrm{M}$ & $10 \mathrm{~g}$ & 2.47 & $4.65 \mathrm{~g}$ & $46.5 \%$ \\
8 & $7 \mathrm{M}$ & $5 \mathrm{~g}$ & 4.95 & $1.55 \mathrm{~g}$ & $31 \%$ \\
9 & $1 \mathrm{~L} 1 \mathrm{M}$ & $10 \mathrm{~g}$ & 1.19 & 0 & 0 \\
10 & $1 \mathrm{~L} 2 \mathrm{M}$ & $10 \mathrm{~g}$ & 1.54 & $5.93 \mathrm{~g}$ & $59.3 \%$ \\
\hline
\end{tabular}

Although no specific explanations have been given for the different powder yields under different ball size distribution and BPR values, it is possible for us to optimize the milling process by changing the size and amount of the grinding medium. We chose the configuration in sample 7 to perform the rest ball milling experiments for a relatively good powder yield and a suitable BPR value.

\subsection{Synthesis of ODS Copper Alloy}

\subsubsection{Addition of $\mathrm{CuO}$}

Figure 1 shows the XRD patterns of $\mathrm{Cu}-\mathrm{Nb}$ and $\mathrm{Cu}-\mathrm{Mo}$ alloys after the addition of $\mathrm{CuO}$ at the beginning of milling. The powder diffraction file (PDF) database is used to identify the phases in the XRD patterns, PDF card numbers of each phase are listed in Appendix A. The broadening of reflections is caused by the reduction of grain size and the microstrains. Peak shifts to lower angles of $\mathrm{Cu}$ at $\left(\begin{array}{lll}1 & 1 & 1\end{array}\right)$ and $(200)$ plane are noticed both in Figure 1a,b, indicating the dissolutions of $\mathrm{Ag}$ and possible $\mathrm{Nb} / \mathrm{Mo}$ in copper matrix. For immiscible alloy systems with high heats of mixing like $\mathrm{Cu}-\mathrm{Nb}$ and $\mathrm{Cu}-\mathrm{Mo}$, the solubilities are extremely low and the corresponding XRD peaks will exist even after a long time of high-energy ball milling [24,31]. However, with the help of $\mathrm{CuO}$, a vanishing of $\mathrm{Nb}$ reflections can be observed after $10 \mathrm{~h}$ of ball milling, see Figure $1 \mathrm{a}$. The calculation of the solubility of $\mathrm{Nb}$ was performed based on the lattice change by applying Vegard's law and using the data of [32] for the lattice Cu-11.76 at.\% $\mathrm{Ag}$ (assuming $75 \mathrm{Cu}$ atoms and $10 \mathrm{Ag}$ atoms in this alloy) as $3.6704 \AA$. The lattice parameters of $\mathrm{Cu}$ of $10 \mathrm{~h}, 20 \mathrm{~h}$, and $30 \mathrm{~h}$ are $3.6770 \AA, 3.6790 \AA$ and $3.6686 \AA$ in Figure 1a. The lattice parameter of $\mathrm{Nb}$ with fcc structure should be $4.1575 \AA$, which was calculated using molecular dynamics method. According to Vegard's law, the solubilities can be obtained as $1.35 \%, 1.77 \%$ and $-0.37 \%$. Thus, Ag powder in matrix may not all in solution or part of the powder get lost when processing. Additionally, Vegard's law is an empirical rule. Therefore, we find that it is difficult to figure out whether or not can the integration of $\mathrm{Nb} / \mathrm{Mo}$ affect the $\mathrm{Cu}$ diffraction shift. It is possible that the oxygen extends the solubility of $\mathrm{Nb}$ here, however, it cannot be the only reason of the total vanishing of $\mathrm{Nb}$ in XRD patterns; otherwise, a larger shift of $\mathrm{Cu}$ diffraction would happen if most of the $\mathrm{Nb}$ get into solution. The reaction between oxygen and $\mathrm{Nb}$ may account for this though no evidence of $\mathrm{Nb}$ oxide existence is found in the X-ray diffraction patterns. In fact, Kim et al. revealed that nano-sized Ti particles in Al matrix were not detected by XRD method and peak disappearance of the minor phase did not reflect 
the formation of true solid solution [33]. Therefore, nano-sized $\mathrm{Nb}$ oxide could possibly formed during the $\mathrm{Cu}_{65} \mathrm{Nb}_{5} \mathrm{Ag}_{10}(\mathrm{CuO})_{10}$ ball milling considering the detection limit of XRD method. Figure $1 \mathrm{~b}$, however, shows a quite different behavior of Mo during ball milling. Peaks of Mo in XRD pattern are found even after milling for $30 \mathrm{~h}$ despite the addition of $\mathrm{CuO}$, indicating a certain portion of $\mathrm{Mo}$ powder is not oxidized by the oxygen from $\mathrm{CuO}$ powder. Although with the intensity reduction of diffraction peaks, it is assumed that Mo have been progressively consumed by oxygen. Notably, a new phase $\mathrm{Cu}_{2} \mathrm{O}$ can be found in the system after $10 \mathrm{~h}$ of milling and disappears before the milling time reaches $20 \mathrm{~h}$. $\mathrm{CuO}$ is believed to have reacted with $\mathrm{Cu}$ to form $\mathrm{Cu}_{2} \mathrm{O}$ in the first $10 \mathrm{~h}$. Generally, a high temperature is needed to initiate this reaction which, on the other hand, shows an advantage of ball milling for making some reactions happen more easily. In this case, $\mathrm{Nb}$ is obviously more easily oxidized than $\mathrm{Mo}$ and it seems that the $\mathrm{CuO}$ powder would rather react with $\mathrm{Cu}$ than Mo. After $30 \mathrm{~h}$ of ball milling with the addition of $\mathrm{CuO}$, the two elements $(\mathrm{Mo}$ and $\mathrm{Nb}$ ) show different phase evolution processes and final states probably due to their different chemical properties. In order to make a better observation of alloying process during ball milling after the addition of $\mathrm{CuO}$, we performed a two-step ball milling procedure.

(a)

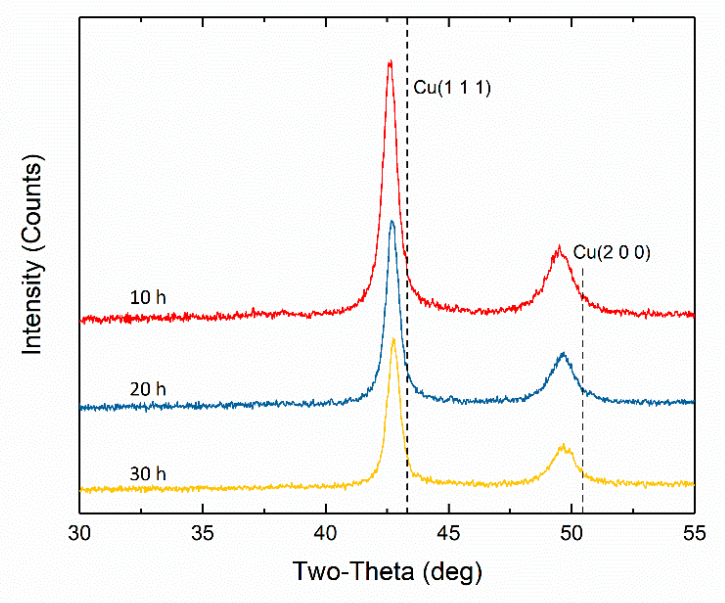

(b)

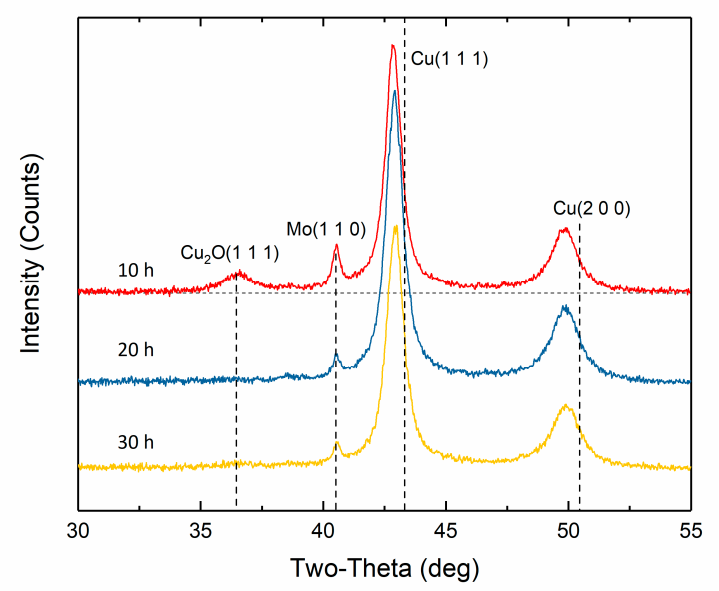

Figure 1. X-ray diffraction patterns of (a) $\mathrm{Cu}_{65} \mathrm{Nb}_{5} \mathrm{Ag}_{10}(\mathrm{CuO})_{10}$ and (b) $\mathrm{Cu}_{65} \mathrm{Mo}_{5} \mathrm{Ag}_{10}(\mathrm{CuO})_{10}$ alloys after 10,20 , and $30 \mathrm{~h}$ of milling.

\subsubsection{Two-Step Ball Milling}

$\mathrm{CuO}$ powder was added into the milling vial after the $\mathrm{Cu}, \mathrm{Nb} / \mathrm{Mo}$ and $\mathrm{Ag}$ powders were pre-milled for $8 \mathrm{~h}$. Powder specimens (less than $0.2 \mathrm{~g}$ each) were taken from the same milling vial after different 
interval of time in the second milling step with a total time of $20 \mathrm{~h}$. We could obtain over $9 \mathrm{~g}$ of fine powder from a total $10 \mathrm{~g}$ of powder added into the vial. The slightly increase of BPR value due to the mass of specimens shouldn't affect the high-energy milling process much as we discussed above. What is notable here is that we can always get a high powder yield (over $90 \%$ ) after the addition of $\mathrm{CuO}$ powder. It seems that the present of oxygen can reduce the effect of excessive cold welding which is consistent with what Madavali et al. [21] and Hegedûs et al. [22] found in their studies.

Figure 2 depicts the $X$-ray diffraction patterns obtained from the powder specimens with varying second-step milling times. The different values after " $8+$ " are the milling times of the second step. Again, the peak shifts to lower angles of $\mathrm{Cu}$ and the broadening of peaks are observed; the disappearance of $\mathrm{Nb}$ peaks and the existence of Mo peaks with the addition of $\mathrm{CuO}$ are shown in Figure 2a,b. One of the differences in Figure 2 is that the peaks of Mo oxide $\left(\mathrm{MoO}_{2}\right)$ are obvious in XRD patterns after milling for $10 \mathrm{~h}$ in second step, unlike what is shown in Figure 1b. Thus, we can confirm the existence of Mo oxide precipitates and we believe that a "two-step" ball milling procedure makes the oxidation process of Mo easier with finely dispersed Mo precipitates in copper matrix after $8 \mathrm{~h}$ milling in first step. Note that $\mathrm{Cu}_{2} \mathrm{O}$ phase forms in both $\mathrm{Nb}$ and Mo alloy at the beginning of the second-step milling. However, peaks of $\mathrm{Cu}_{2} \mathrm{O}$ disappear before $4 \mathrm{~h}$ in Figure $2 \mathrm{a}$ and exist after $20 \mathrm{~h}$ in Figure $2 \mathrm{~b}$. This suggests that the oxidation process of $\mathrm{Nb}$ is easier and faster than that of Mo.

(a)

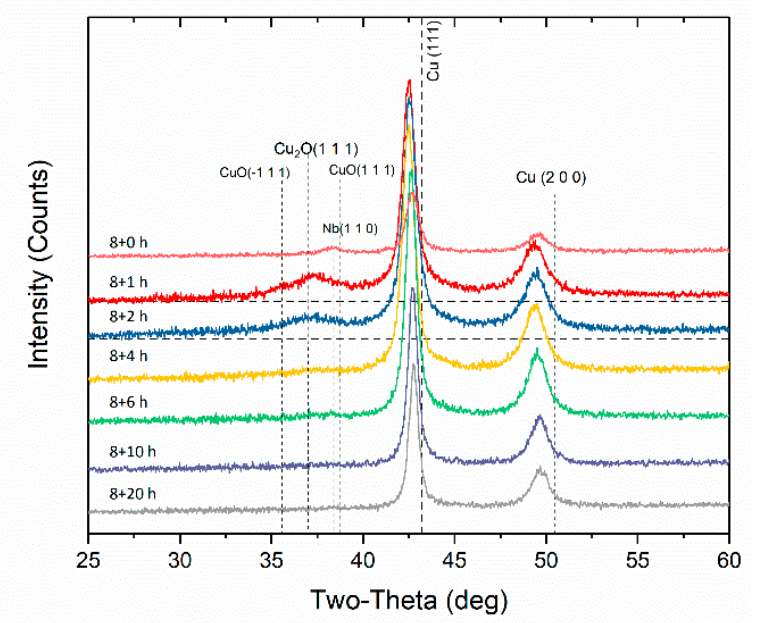

(b)

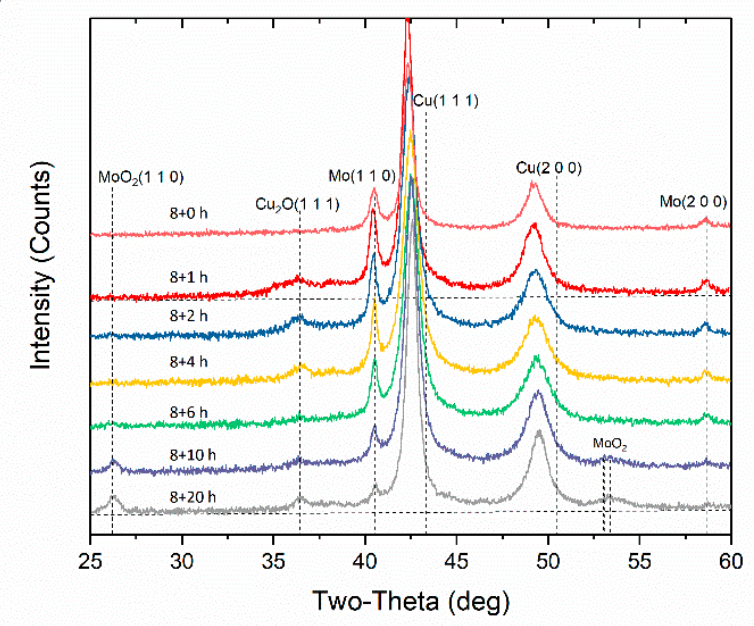

Figure 2. X-ray diffraction patterns of (a) $\mathrm{Cu}_{65} \mathrm{Nb}_{5} \mathrm{Ag}_{10}(\mathrm{CuO})_{10}$ and $(\mathbf{b}) \mathrm{Cu}_{65} \mathrm{Mo}_{5} \mathrm{Ag}_{10}(\mathrm{CuO})_{10}$ alloys as a function of second-step milling time. 
The high-angle annular dark field (HAADF) images of $\mathrm{Cu}-\mathrm{Nb}$ and $\mathrm{Cu}-\mathrm{Mo}$ alloys after milling are shown in Figure 3. Although with no signs of $\mathrm{Nb}$ oxide in Figure 2a, the images in Figure 3 reveal the existence and the morphology of both $\mathrm{Nb}$ and Mo oxide precipitates. As Z-contrast imaging is used in HAADF images, the intensity in imaging is proportional to the square of the average atomic number, suggesting the dark precipitates should be $\mathrm{Nb} / \mathrm{Mo}$ oxide precipitates. Energy dispersive spectroscopy (EDS) results also show that the dark regions are rich in $\mathrm{Nb} / \mathrm{Mo}$ and oxygen. Note that the Mo oxide precipitates are uniformly dispersed in $\mathrm{Cu}$ matrix with a narrow size distribution as shown in Figure $3 \mathrm{~b}$. However, the $\mathrm{Nb}$ oxide precipitates in Figure 3a are mainly composed of two types of precipitates with different sizes, smaller type less than $10 \mathrm{~nm}$ and the other around $20-50 \mathrm{~nm}$. Except the different tendencies to be oxidized, we suggest the large difference of the shear modules of $\mathrm{Nb}$ ( $38 \mathrm{Gpa}$ ) and $\mathrm{Mo}$ (120 Gpa) could also be related to the different behaviors of these two alloys. Since the shear modulus is proportional to the Peierls-Nabarro stress, which is the force needed to move a dislocation, the $\mathrm{Nb}$ precipitates are easier to be cut by dislocations during deformation. This process introduces more interfaces, which makes more diffusion between elements, and together with a higher tendency to be oxide in $\mathrm{Nb}$ alloy as we described before, explain the faster oxidation process of $\mathrm{Nb}$ compared with Mo. It takes a longer time before the reaction between $\mathrm{Cu}_{2} \mathrm{O}$ and Mo particles, because of the low diffusivity of Mo, probably the size of both $\mathrm{Mo}$ and $\mathrm{Cu}_{2} \mathrm{O}$ particles should be small enough before the formation of Mo oxide precipitates, leading to a homogeneous morphology. The larger precipitates in Figure $3 \mathrm{a}$ are possibly transformed from deformed $\mathrm{Cu}_{2} \mathrm{O}$ particles which react with $\mathrm{Nb}$ before the size being reduced to below $20 \mathrm{~nm}$ by ball milling. The $\mathrm{Nb}$ in solution is supposed to precipitate out from $\mathrm{Cu}$ matrix and then be oxidized, resulting in small precipitates $(<10 \mathrm{~nm})$ in Figure 3a. It can, therefore, be concluded that the different evolution processes and morphologies of $\mathrm{Mo}$ and $\mathrm{Nb}$ alloys during ball milling are related to their different tendencies to be oxidized and shear modules.
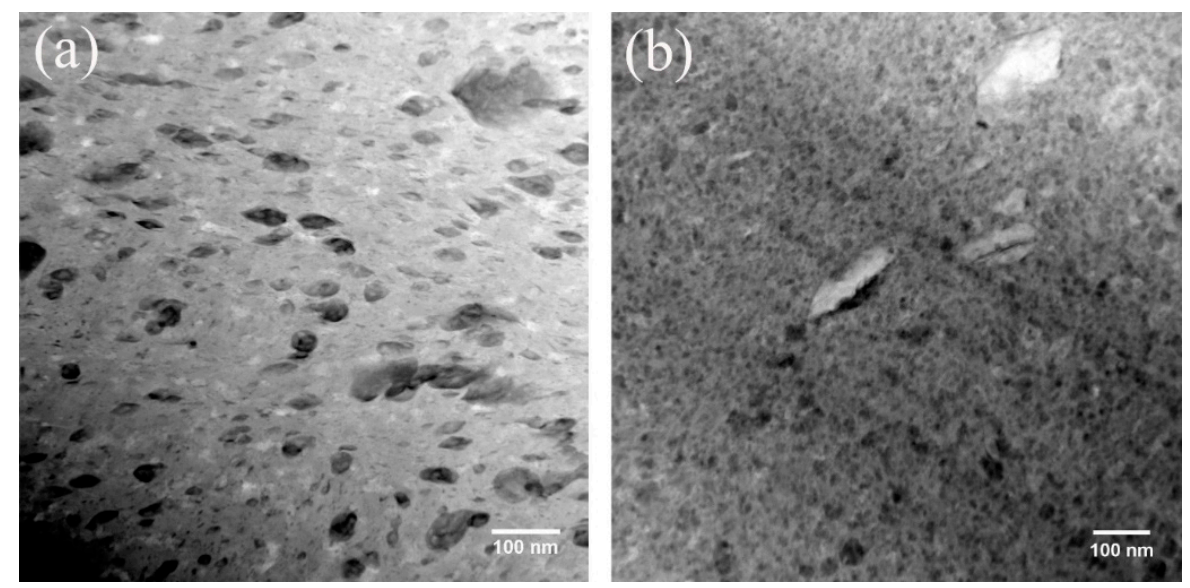

Figure 3. HAADF images of (a) $\mathrm{Cu}_{65} \mathrm{Nb}_{5} \mathrm{Ag}_{10}(\mathrm{CuO})_{10}$ alloy ball milled for $(8+4) \mathrm{h}$; and $(\mathbf{b})$ $\mathrm{Cu}_{5} \mathrm{Mo}_{5} \mathrm{Ag}_{10}(\mathrm{CuO})_{10}$ alloy ball milled for $(8+20) \mathrm{h}$.

\section{Summary and Conclusions}

The influences of processing parameters on mechanical alloying were discussed and investigated in this study to optimize this synthesis method. Ball milling experiments on $\mathrm{Cu}-\mathrm{Nb}$ and $\mathrm{Cu}-\mathrm{Mo}$ alloys were performed at room temperature with the addition of $\mathrm{CuO}$ powders and a "two-step" ball milling method was introduced in order to evaluate the different evolution processes and morphologies in different alloy systems. We discussed how the chemical and mechanical properties of different elements affect the ball milling process and the final state of milled powder. Based on the results and previous analysis, the following conclusions can be drawn:

1. High powder yields can be obtained by changing the BPR value and ball size distribution.

2. No clear dependence of BPR value on powder yield can be found from the experiment results. 
3. The addition of oxygen can largely reduce the effect of excessive cold welding during ball milling.

4. A "two-step" ball milling procedure considerably benefits the oxidation process of Mo and shows its promising potential in the synthesis of immiscible alloys.

5. The chemical and mechanical properties of elements play a critical role in the evolution process and morphologies of different alloys during milling.

Author Contributions: Investigation: X.S.; methodology: S.C.; supervision: X.W.; writing—original draft: X.S.; writing-review and editing: X.W. and S.C.

Funding: This research received no external funding.

Conflicts of Interest: The authors declare no conflict of interest.

\section{Appendix A}

The PDF data used for the identification of phases in the XRD patterns are as follows: Cu-PDF\#01-085-1326; Nb-PDF\#04-012-8010; Mo-PDF\#04-001-0059; Ag-PDF\#04-001-2617; CuO-PDF \#04-007-1375; $\mathrm{Cu}_{2} \mathrm{O}-\mathrm{PDF} 04-007-9767 ; \mathrm{NbO}_{2}-\mathrm{PDF} 04-001-1744 ; \mathrm{MoO}_{2}-\mathrm{PDF} 01-086-0135$.

\section{References}

1. Gilman, P.S.; Benjamin, J.S. Mechanical Alloying. Annu. Rev. Mater. Sci. 1983, 13, 279-300. [CrossRef]

2. Suryanarayana, C. Mechanical alloying and milling. Prog. Mater. Sci. 2001, 46,1-184. [CrossRef]

3. Benjamin, J.S. Dispersion strengthened superalloys by mechanical alloying. Metall. Trans. 1970, 1, 2943-2951. [CrossRef]

4. Benjamin, J.S.; Volin, T.E. The mechanism of mechanical alloying. Metall. Trans. 1974, 5, 1929-1934. [CrossRef]

5. Zhang, D.L. Processing of advanced materials using high-energy mechanical milling. Prog. Mater. Sci. 2004, 49, 537-560. [CrossRef]

6. Razavi-Tousi, S.S.; Szpunar, J.A. Effect of ball size on steady state of aluminum powder and efficiency of impacts during milling. Powder Technol. 2015, 284, 149-158. [CrossRef]

7. Canakci, A.; Varol, T.; Ozsahin, S. Analysis of the effect of a new process control agent technique on the mechanical milling process using a neural network model: Measurement and modeling. Meas. J. Int. Meas. Confed. 2013, 46, 1818-1827. [CrossRef]

8. Hosseini-Gourajoubi, F.; Pourabdoli, M.; Uner, D.; Raygan, S. Effect of process control agents on synthesizing nano-structured $2 \mathrm{Mg}-9 \mathrm{Ni}-\mathrm{Y}$ catalyst by mechanical milling and its catalytic effect on desorption capacity of $\mathrm{MgH}_{2}$. Adv. Powder Technol. 2015, 26, 448-453. [CrossRef]

9. Nouri, A.; Hodgson, P.D.; Wen, C.E. Effect of process control agent on the porous structure and mechanical properties of a biomedical Ti-Sn-Nb alloy produced by powder metallurgy. Acta Biomater. 2010, 6, 1630-1639. [CrossRef]

10. Gheisari, K.; Javadpour, S. The effect of process control agent on the structure and magnetic properties of nanocrystalline mechanically alloyed Fe-45\% Ni powders. J. Magn. Magn. Mater. 2013, 343, 133-137. [CrossRef]

11. Kurama, H.; Erkuş, Ş.; Gaşan, H. The effect of process control agent usage on the structural properties of MgB2synthesized by high energy ball mill. Ceram. Int. 2017, 43, S391-S396. [CrossRef]

12. Lee, W.; Kwun, S.I. The effects of process control agents on mechanical alloying mechanisms in the Ti-Al system. J. Alloys Compd. 1996, 240, 193-199. [CrossRef]

13. Wu, Z.; Liang, Y.; Fu, E.; Du, J.; Wang, P.; Fan, Y.; Zhao, Y. Effect of Ball Milling Parameters on the Refinement of Tungsten Powder. Metals 2018, 8, 281. [CrossRef]

14. Chauruka, S.R.; Roberts, K.J.; Stitt, H.; Hassanpour, A.; Brydson, R.; Ghadiri, M. Effect of mill type on the size reduction and phase transformation of gamma alumina. Chem. Eng. Sci. 2015, 134, 774-783. [CrossRef]

15. Beranoagirre, A.; Olvera, D.; López De Lacalle, L.N. Milling of gamma titanium-aluminum alloys. Int. J. Adv. Manuf. Technol. 2012, 62, 83-88. [CrossRef]

16. Ward, T.S.; Chen, W.; Schoenitz, M.; Dave, R.N.; Dreizin, E.L. A study of mechanical alloying processes using reactive milling and discrete element modeling. Acta Mater. 2005, 53, 2909-2918. [CrossRef] 
17. Qu, S.; Li, X.; Li, Y.; Hu, L.; Wang, E. Manufacturing a TiAl alloy by high-energy ball milling and subsequent reactive sintering. Rare Met. 2006, 25, 21-26. [CrossRef]

18. Gotor, F.J.; Achimovicova, M.; Real, C.; Balaz, P. Influence of the milling parameters on the mechanical work intensity in planetary mills. Powder Technol. 2013, 233, 1-7. [CrossRef]

19. Mojarrad, N.R.; Kheirifard, R.; Mousavian, R.T.; Afkham, Y.; Nakisa, S. Filling ratio of vial. J. Therm. Anal. Calorim. 2016, 126, 1097-1103. [CrossRef]

20. Broseghini, M.; D'Incau, M.; Gelisio, L.; Pugno, N.M.; Scardi, P. Effect of jar shape on high-energy planetary ball milling efficiency: Simulations and experiments. Mater. Des. 2016, 110, 365-374. [CrossRef]

21. Madavali, B.; Lee, J.-H.; Lee, J.K.; Cho, K.Y.; Challapalli, S.; Hong, S.-J. Effects of atmosphere and milling time on the coarsening of copper powders during mechanical milling. Powder Technol. 2014, 256, 251-256. [CrossRef]

22. Hegedús, Z.; Meka, S.R.; Mittemeijer, E.J. In situ consolidation of ball milled metals. J. Alloys Compd. 2017, 695, 721-725. [CrossRef]

23. Caballero, E.; Cintas, J.; Cuevas, F.; Montes, J.; Ternero, F. Influence of Milling Atmosphere on the Controlled Formation of Ultrafine Dispersoids in Al-Based MMCs. Metals 2016, 6, 224. [CrossRef]

24. Wang, M.; Averback, R.S.; Bellon, P.; Dillon, S. Chemical mixing and self-organization of Nb precipitates in Cu during severe plastic deformation. Acta Mater. 2014, 62, 276-285. [CrossRef]

25. Kuziora, P.; Wyszyńska, M.; Polanski, M.; Bystrzycki, J. Why the ball to powder ratio (BPR) is insufficient for describing the mechanical ball milling process. Inter. J. Hydrogen Energy 2014, 39, 9883-9887. [CrossRef]

26. Padella, F.; Paradiso, E.; Burgio, N.; Magini, M.; Martelli, S.; Guo, W.; Iasonna, A. Mechanical alloying of the Pd-Si system in controlled conditions of energy transfer. J. Less Common Met. 1991, 175, 79-90. [CrossRef]

27. Guo, W.; Iasonna, A.; Magini, M.; Martelli, S.; Padella, F. Synthesis of amorphous and metastable $\mathrm{Ti}_{40} \mathrm{Al}_{60}$ alloys by mechanical alloying of elemental powders. J. Mater. Sci. 1994, 29, 2436-2444. [CrossRef]

28. Park, Y.H.; Hashimoto, H.; Watanabe, R. Morphological Evolution and Amorphization of Ti/Cu and Ti/Al Powder Mixtures during Vibratory Ball Milling. Mater. Sci. Forum 1992, 88-90, 59-66. [CrossRef]

29. Tcherdyntsev, V.V.; Kaloshkin, S.D.; Tomilin, I.a.; Shelekhov, E.V.; Serdyukov, V.N. Alloy Formation at Ball Milling of $\mathrm{Cu}_{50} \mathrm{Cr}_{50}$ and $\mathrm{Fe}_{86.5} \mathrm{Cu}_{13.5}$ Compositions. Mater. Sci. Forum 2001, 360-362, 361-366. [CrossRef]

30. Takacs, L.; Pardavi-Horvath, M. Nanocomposite formation in the $\mathrm{Fe}_{3} \mathrm{O}_{4}$ - Zn system by reaction milling. J. Appl. Phys. 1994, 75, 5864-5866. [CrossRef]

31. Botcharova, E.; Freudenberger, J.; Schultz, L. Mechanical alloying of copper with niobium and molybdenum. J. Mater. Sci. 2004, 39, 5287-5290. [CrossRef]

32. Linde, R.K. Lattice Parameters of Metastable Silver-Copper Alloys. J. Appl. Phys. 1966, 37, 934. [CrossRef]

33. Kim, H.S.; Suhr, D.S.; Kim, G.H.; Kum, D.W. Analysis of X-ray diffraction patterns from mechanically alloyed Al-Ti powders. Met. Mater. 1996, 2, 15-21. [CrossRef] 